\title{
Generic Overlap Between Publication Genres: The Case of Biology Research Articles' and Research Letters' Introductions in the Journal Nature
}

\author{
Mimoun Melliti ${ }^{1}$ \\ ${ }^{1}$ Faculty of Letters and Human Sciences, University of Kairouan, Tunisia \\ Correspondence: Mimoun Melliti, Faculty of Letters and Human Sciences, University of Kairouan, Tunisia. \\ E-mail: mimoun.militi@flshk.u-kairouan.tn
}

Received: May 25, 2020

Accepted: July 22, 2020

Online Published: November 19, 2020

doi:10.5539/ijel.v11n1p135

URL: https://doi.org/10.5539/ijel.v11n1p135

\begin{abstract}
The present paper explores aspects of similarity and difference between the generic structure of research letters' abstracts (henceforth RLsA) and research articles' abstracts (henceforth RAsA). It aims at investigating and documenting the different rhetorical patterns of 19 RLsA and 19 RAsA in order to identify if there is any unique shared way to write them, determine the most publishable way of writing this genre, and detect any possibility of generic overlap between the two genres. Melliti $(2016,2017)$ CARL model has been adopted to identify the kind, frequency, and overlap of moves in RLsA and RAsA of the Journal Nature. The results indicate that although the RAs are longer than the RLs, the number of sentences in the RLsA is more than the RAsA. Results show also that there are fundamental as well as expendable sets of keys in both genres. The study succeeded also in identifying the number of sentences required to write a publishable research letter abstract and research article abstract in the field of biology. These findings have interesting implication on teaching academic writing and teaching English for publication purposes.
\end{abstract}

Keywords: genre analysis, generic structure, research letter, rhetoric, swales' Model, CARS Model, research publication

\section{Introduction}

Researchers have extensively investigated different kinds of texts and have identified their internal organizational structures. These texts include the research article (Nwogu, 1991; Skelton, 1994; Posteguillo, 1999; Kanoksilapatham, 2005) and its parts: the introduction section (Swales \& Najjar, 1987; Swales, 1990, 2004; Samraj, 2002; Ozturk, 2007), the abstract (Salager-Meyer, 1992, 2006), the results section (Thompson, 1993; Brett, 1994; Williams, 1999; Bruce 2009), the discussion section (Hopkins \& Dudley-Evans, 1988), and the methods section (Lim, 2006; Bruce, 2009). Additionally, previous studies covered also the business letter (Bhatia, 1993), the university lecture (Thompson, 1994), the fundraising letter (Biber, Connor, \& Upton, 2007), the newspaper law report (Badger, 2003), the dissertation (Hopkins \& Dudley-Evans, 1988; Samraj, 2008), the editorial letter (Flowerdew \& Dudley-Evans, 2002) etc.

\section{Literature Review}

Genre has been defined differently by scholars according to orientations and perspectives. However, in this study the researcher adopts the definition of genre given by Bhatia (1997) who considers genre as the study of linguistic behavior in institutionalized academic or professional settings.

Early definitions of genre depict it as predetermined, unchallengeable and homogenous while recent definitions of genre view it as livelier (Connor, 1996; Swales, 2004). This new definition of genre, which is influenced by the theories of Bakhtin (1986) is put forward by Connor (1996) as follows:

Genres are not static, stylistically homogenous texts. Although texts, according to Bakhtin, have ordered, unified forms (for example, stories have a structure) they are also "intertextual": that is, texts are ongoing processes of discourse production and reception that are always tied to other texts or utterances in a culture (1996, p. 128).

Swales $(1990,2004)$, whose research has been very influential in genre theory, has introduced "moves" or 
"functional components" as essential elements of genre. According to him, genres are "communicative events" that are characterized both by their communicative purposes and by a variety of patterns of structure, style, content and intended audience. Swales' $(1990,2004)$ model of genre analysis, move structure analysis, classifies segments of texts according to their prototypical communicative purpose for a particular genre. In this respect, his model has been used as a framework in ESP research that focus on the analysis and teaching of the spoken and written language required of non-native speakers in academic and professional settings (Hyon, 1996).

RLs are small reports of pioneering research focused on extraordinary results. The most important advantage that RLs offer is the rapid review and publication. As briefly put by Rutkowski and Ehrenfest (2012), "the research letter is an autonomous format for the rapid publication of data (...) [as the] concept of this format is to publish quickly good preliminary data (or data obtained with a simple protocol) in a short format" (p. 102). Its autonomy means that there is a strong possibility for being different from other genres and formats in terms of generic organization, which is, eventually, the issue that this research article seeks to explore.

Throughout history, researchers have used several ways to report science. Among these methods, one could list books, magazines, newspapers, journals, editorials, research articles, reviews, letters to the editor, and the RL. In an attempt to investigate the generic layout of texts reporting scientific research, researchers used various frameworks, approaches, and tools.

This work makes use of genre analysis to explore the way RLsA and RAsA in biology are organized in terms of their common rhetorical structure. This means investigating and documenting the different rhetorical patterns of 19 RLsA and 19 RAsA in order to identify the unique shared way to write them, to determine the most publishable way of writing this genre, and detect any possibility of overlap between the two genres.

The notion of genre has been used to investigate several domains (Del Arbol, 2005) such as linguistic anthropology, folklore studies, conversational analysis, the ethnography of communication, the sociology of language, applied linguistics, and literary theory and rhetoric.

For Swales (1990):

A genre comprises a class of communicative events, the members of which share some set of communicative purposes. These purposes are recognized by the expert members of the parent discourse community, and thereby constitute the rationale for the genre (p. 58).

This means that for a genre to be recognized it necessitates primarily encompassing a set of common features. These features create (or may be are created by) a particular group of community members and experts. Although genre remains a blurry concept, it could be defined as "the study of situated linguistic behavior in institutionalized academic or professional settings" (Swales, 1990, p. 629). This fuzziness may be the result of the variability in the ways of addressing genre. For Berkenkotter and Huckin (1995), genre is considered typification of rhetorical action. However, for Martin, Christy and Rothery (1987) and Martin (1993) it is regularities of staged goal oriented social processes. Besides, for Swales (1990) and Bhatia (1993), genre is looked at in terms of consistency of communicative purposes.

In spite of these differences, these orientations share three main common features, which are "emphasis on conventional knowledge, (...) versatility of generic description, (...) and propensity for innovation" (Swales, 1990, p. 630).

The present work attempts to explore the rhetorical conventional rules governing the construction of RLsA being an emergent genre (Maci, 2009; Gotti, 2007) in scientific writing. It aims also at comparing the generic structure of RLsA to that of RAsA. In an attempt to structure the RL genre, some journals suggest different forms of constructing letters. Such difference is what necessitates the unification of the rhetorical structures of this genre. The ultimate aim is to make it more comprehensible to readers and easy to write for scientists all around the globe, and especially non-Anglophone scientists who are striving to be published authors. An example of the RL's layout that journals provide is the one suggested by Nature in the following diagram. 


\begin{tabular}{|c|c|}
\hline $\begin{array}{l}\text { One or two sentences providing a basic introduction to the field, } \\
\text { comprehensible to a scientist in any discipline. }\end{array}$ & \multirow{10}{*}{ 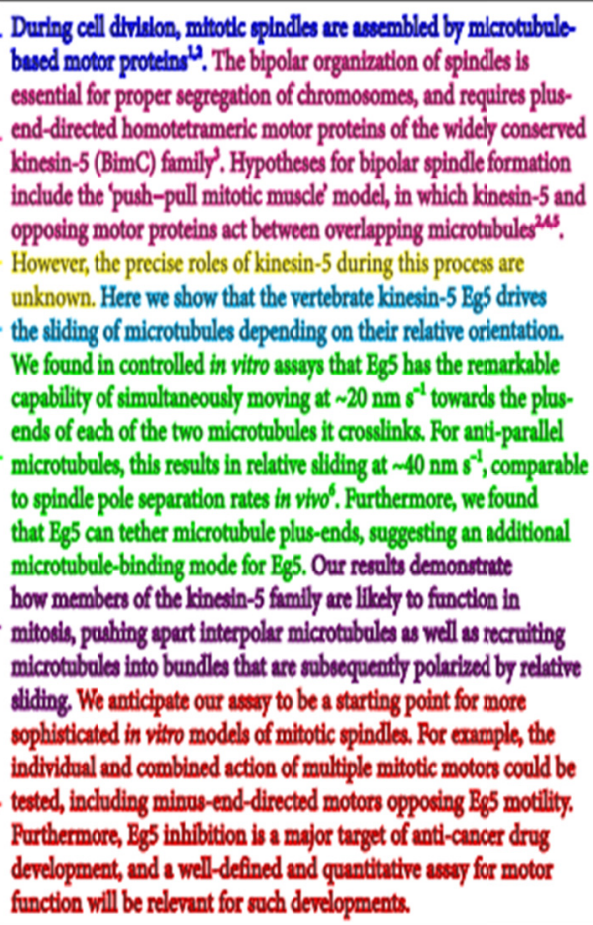 } \\
\hline Two to three sentences of more detailed background, comprehensible & \\
\hline to scientists in related disciplines. & \\
\hline $\begin{array}{l}\text { One sentence clearly stating the general problem being addressed by } \\
\text { this particular study. }\end{array}$ & \\
\hline $\begin{array}{l}\text { One sentence summarixing the main result (with the words "here we } \\
\text { show" or their equivalent). }\end{array}$ & \\
\hline $\begin{array}{l}\text { Two or three sentences explaining what the main result reveals in direct } \\
\text { comparison to what was thought to be the case previously, or how the } \\
\text { main result adds to previous knowledge. }\end{array}$ & \\
\hline & \\
\hline One or two sentences to put the results into a more general context. & \\
\hline $\begin{array}{l}\text { Two or three sentences to provide a broader perspective, readily } \\
\text { comprehensible to a scientist in any discipline, may be included in the } \\
\text { first paragraph if the editor considers that the accessibility of the paper }\end{array}$ & \\
\hline $\begin{array}{l}\text { is significantly enhanced by their inclusion. Under these circumstances, } \\
\text { the length of the paragraph can be up to } 300 \text { words. (This example is } \\
190 \text { words without the final section, and } 250 \text { words with it). }\end{array}$ & \\
\hline
\end{tabular}

Figure 1. Annotated example taken from Nature 435, 114-118 (5 May 2005).

In another journal, the editors suggest the general structure that scientists are requested to use when writing their research letters. They advocate that

[t]hese letters are normally built in 3 parts: introduction, description of the method and result, and discussion. Like all letters, they do not have an abstract. In these letters, authors should use no more than 1500 words and 25 references. Explanatory and graphic pictures (up to a maximum of 15) are highly recommended in this format (Rutkowski \& Ehrenfest, 2012, p. 102).

Another example of letters resorted to by researchers to report and criticize science is Letters to the editor (henceforth Lte), which are said to have appeared since the 18th century in newspapers and magazines (Wahl-Jorgensen, 2007). They are short articles used to expose viewpoint as to previously published articles and/or to explain short scientific information that do not necessitate the length of research articles (Del Arbol, 2005).

For Webber (1994) "Letters to the Editor is one of the seven genres identified in scientific journals along with research papers, review articles, editorials, book reviews, case studies and the news section" (qtd in Magnet \& Carnet, 2006, p. 175). It is important to mention at this level that RL are not indicated and recognized as a distinct genre in scientific research. Magnet and Carnet (2006) claim that in the Physical Review journal the letters-to-the-editor column "had become so important that the publishers decided to issue it as a separate publication, thus giving birth o cially to PRL (Physical Review Letters)" (p. 174). Lte are considered peer commentaries valorizing, editing or expressing total disagreement with findings and claims in particular scientific articles (Wahl-Jorgensen, 2007).

RLs are an under-researched genre and this shortage could be explained by the fact that linguists have most of the time focused on the research article being the dominant mode of scientific knowledge production (Swales, 1984; Nwogu, 1991; Williams, 1999).

Swales (1990) investigated the introduction of research articles and Holmes (1997) and Hopkins and Dudley-Evans (1988) worked on discussion section. Additionally, Anderson and Maclean (1997) and Salagar-Meyer (2006) explored the rhetorical structure of medical English abstracts, and Williams (1999) and Brett (1994) examined the results section of academic articles. In the same vein, and within contrastive rhetoric (henceforth CR) studies, Taylor and Chen (1991) conducted a study on similarities and difference between 
Chinese and Anglo-American scientists concerning the science paper introductions.

In her analysis of Lte, Del Arbol (2005, p. 156) found that they are composed of 3 moves and 11 steps. Comparing editorials to Lte, Del Arbol (ibid) found that the structure of the latter is more rigid than the former and she returned this to the fact that "each genre may have unique linguistic patterns which are not shared with the rest" (p. 157). However, the study conducted by Del Arbol (2005) could be considered limited for it focused only on 25 Lte.

Swales (1990) developed a model for research articles introductions based on studying numerous corpora. He found that academic articles are basically composed of three moves: establishing a territory, establishing a niche, and occupying the niche. Based on this model, various research studies have been conducted in order to assess CR claims that written discourse structure differs in relation to the linguistic background of the writer (Taylor \& Chen, 1991).

Based on Swales (1990) model, Paltridge (1997) developed a model to analyze 12 research articles on environment studies. The model consists of a number of keys or terms symbolizing structural elements in the RLs investigated and aiming at indicating the frequency of their occurrence in the corpora:

BI Background Information

JS Justification for Study
IG Indicating a Gap
PS Purpose of Study
RS Rationale for Study
QR Question Raising
PR Previous Research
CS Context of Study
M Materials
R Results
C Conclusions

A modified version of this model has been used by Melliti (2016) to identify the generic structure of 37 RLs dealing with different disciplines. Suggesting what he called Create A Research Letter Introduction Model (CARL Introduction Model), he found that RLs' abstracts are composed 12 sentences of which 7 are obligatory and 5 are optional. The model has also been used by Melliti (2017) to identify what he called Create A Research Letter Body Model (CARL Body Model). He found that the body section of RLs is composed of 58 sentences where 49 are obligatory and 9 are optional. These findings are important as they assist researchers in scientific disciplines in their attempt to write publishable research letters and help EAP teachers teach writing in a structured and standardized way.

It is important to investigate the rhetorical structure of different genres and sub-genre such as RL as this helps scientists become aware of the patterns of this mode of scientific contribution in knowledge production. It is crucial also for it assists ESP teachers in identifying the organizational structure of RLs and teach them effectively to learners as according to Henry and Roseberry (2001) "ESP practitioners need to be aware of not just this range of features, but where they are used and for what purpose" (p. 167).

\section{Methods}

The model of Swales (2004) has been adopted to be compared with the model of research letters identified by the researcher. In order to identify the generic structure potential, Swales (2004) suggested the following Moves and Steps Create a Research Space (CARS) model.

Figure 1: CARS model

Move 1

Establishing a territory

Move 2 Establishing a niche

Step 1A: Indicating a gap or

Step 1B: Adding to what is known 
Step 2: Presenting positive justification (optional)

Move 3 Presenting the present work

Step 1: Announcing present research descriptively AND/OR purposively (obligatory)

Step 2: Presenting research questions or hypotheses* (optional)

Step 3: Definitional clarifications* (optional)

Step 4: Summarizing methods* (optional)

Step 5: Announcing principle outcomes (optional)**

Step 6: Stating the value of the present research (optional)**

Step 7: Outlining the structure of the paper (optional)**

The researcher resorted to Melliti $(2016,2017)$ CARL model in order to extract the rhetorical patterns of 19 Biology RLsA and 19 Biology RAsA randomly downloaded from Nature journal.

RLsA and RAsA were selected and analyzed sentence by sentence. Each sentence was allocated a particular structural element or key according to its function. The occurrence and frequency of these functions in the introduction of each RL were counted in order to identify the shared rhetorical patterns between the 19 RLsA and 19 RAsA randomly selected from the journal Nature. The aim is to contribute to the effort of identifying the hidden structure of this new and under researched genre.

\section{Results and Discussion}

\subsection{Types and Distribution of Keys in RAsA and RLsA}

The results obtained indicate the presence of 14 types of keys in RLsA. These keys are:

Background Information (BI)

Justification of Study (JS)

Identification of Gap (IG)

Purpose of Study (PS)

Rationale of Study (RS)

Previous Research (PR)

Results (R)

Conclusions (C)

Previous Research/Background Information (PR/BI)

Methodology (M)

Results/Conclusions (R/C)

Previous Research/Identification of Gap (PR/IG)

Methodology/Results (ME/R)

Future Research (FR)

The above-mentioned keys are the different moves constructing the abstracts of RLs. They are resorted to by Biology researchers in their 'abstracting' process to give the readers an idea about the paper, its context, results, and implications. Needless to mention that the frequency of the moves is not the same in the structure of RLsA. Some moves are mentioned more frequently than others. For example, the BI move is mentioned 20 times in the 19 Biology RLs while FR is mentioned only once. This inequality in moves distribution in RLsA shows that some moves are more valued than others in the generic structure of this genre. It could be explained by the fact that the researcher does not necessarily need to expect future studies with regard to the issue tackled in the RL at the abstract phase. It is so as the aim of the abstract is primarily to contextualize the study and expose its results.

On the other hand, the results indicate that the RAsA are composed of only 8 kinds of moves:

Background Information (BI)

Identification of Gap (IG)

Background Information/Identification of Gap (BI/IG) 
Purpose of Study (PS)

Purpose of Study/Methodology (PS/ME)

Results (R)

Conclusions (C)

Methodology/Results (ME/R)

Surprisingly, the kinds of moves of RAsA are only $57.1 \%$ of RLsA' ones, which means that the RAsA are shorter than the RLsA. Naturally, if the RA genre is longer than the RL genre this should be reflected in the length of the different sections of the journal. However, it has been discovered in the present study that this does not necessarily apply on the abstract section. This could be explained by the fact that the RA has more opportunities to focus on other moves in the body and conclusion sections while the RL has only limited number of pages.

The results also indicate that the dissemination of the keys varies not only across both genres but also across the keys themselves in RAsA. The number of times a particular key is mentioned differs from other keys, which reflects the importance allocated to it by author. The figure below shows the total number of mention of each key in the RAsA.

\section{Total Number per key out of 130}

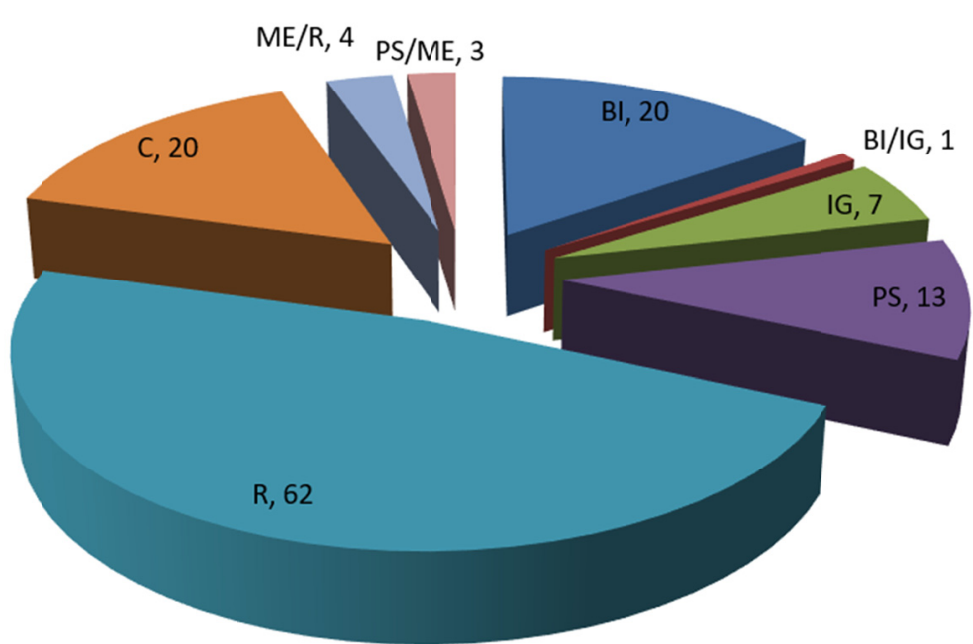

Figure 2. Keys distribution in RAsA

The figure above shows that results-related sentences dominate RAsA. This dominant key constitutes 62 out of the total number of keys in RAsA, which is 130 . This means that about half of all sentences in RAsA deal with the results found in the study conducted.

Similarly, the results also indicate that in RLsA, the number of times a particular key is mentioned differs from other keys. The figure below shows the total number of mention of each key in the RLsA. 


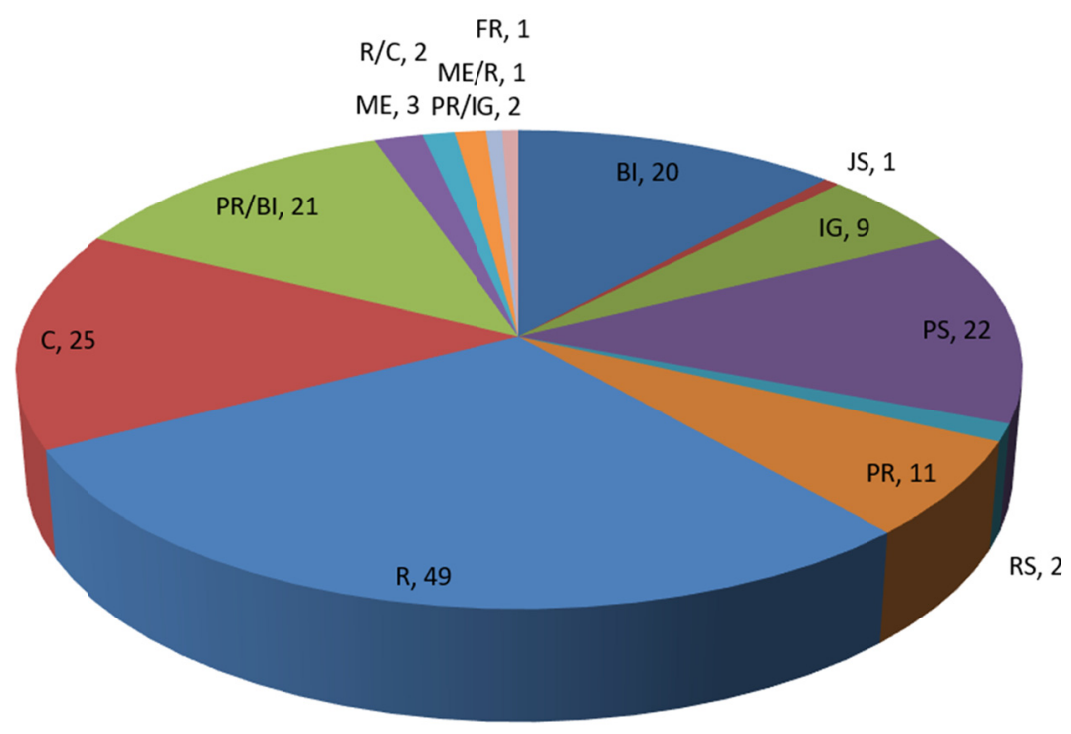

Total number of mention per key out of 169

Figure 3. Keys distribution in RLsA

Just like the findings of RAsA, figure 3 shows that Results-related sentences constitute the biggest number of sentences in RLsA. The number of sentences exposing the results in RLsA is 49 out of the 169 sentences of all 19 RLs investigated. This means that in both genres the results section is clearly predominant.

\subsection{Major Sets of Both Genres}

A major set of keys could be easily identified in RAsA (Figure 2) and it comprises the most mentioned types of sentences. This major set includes the conclusion-related sentences (20), Background Information-related sentences (20), the results-related (62), and Purpose of Study-related sentences (13). These four keys form 115 out of the 130 sentences constituting the RAsA. This means that the RAsA is essentially based on BI, PS, R, and C. It could be said, then, that these four types of sentences compose the core of a publishable RA in biology. In order for a biology research article to be published in a prestigious journal like Nature, it seems it is essential to contain predominantly Background Information, Purpose of Study, Results, and Conclusion sentences. As confirmed in the present study, they form a fundamental part (85.5\%) of the research articles in biology as stated in the table below.

Table 1. Percentage of mention of keys in RAsA

\begin{tabular}{lllllllll}
\hline & BI & BI/IG & IG & PS & R & C & ME/R & PS/ME \\
\hline Average number of mention of keys in RAsA (\%) & 15.4 & 0.8 & 5.4 & 10.0 & 47.7 & 15.4 & 3.1 & 2.3 \\
\hline
\end{tabular}

The table shows also that there is another set of keys. They are called the expendables (in red) in this study as they are numerically relatively marginal in the structure of the RAsA. The issue concerns notably IG, BI/IG, $\mathrm{ME} / \mathrm{R}$, and PS/ME. All of these keys form only $11.5 \%$ of the RAsA.

The major importance given to the first set (the dominant) compared to the minor one given to the second (the expendables) could be attributed to the fact that researchers need to draw considerable attention to their findings and the implications of their results in the abstract section. This is the most appealing part to the readers who are interested in new discoveries more than the review of the literature part and prior to the methodology of the study. The abstract serves the function of the hook in research publication as it is based on readers assessment of it that they decide whether the article is worth reading or not. It is for this reason that researchers mention the best of their findings and conclusions in it.

As far as RLsA are concerned, a similar set of predominant keys could be identified. It comprises Results-related (49), Conclusions-related (25), Previous Research/Background Information-related (21), Purpose of 
Study-related (22), and Background Information-related (20) sentences. Together, they form 137 out of the 169 mentioned sentences in the RLsA analyzed. This set could be then the main part in the structure of the RLsA in biology as it represents $81 \%$ of the total sentences, as illustrated in the table below.

Table 2. Average number of mention of keys in RLs introductions (\%)

\begin{tabular}{|c|c|c|c|c|c|c|c|c|c|c|c|c|c|c|}
\hline & BI & $\mathbf{J S}$ & IG & PS & RS & PR & $\mathbf{R}$ & C & PR/BI & $\mathrm{ME}$ & $\mathrm{R} / \mathrm{C}$ & $\mathrm{PR} / \mathrm{IG}$ & $\mathrm{ME} / \mathrm{R}$ & FR \\
\hline $\begin{array}{l}\text { Percentage of keys in } \\
\text { RLsA (\%) }\end{array}$ & 11.8 & 0.6 & 5.3 & 13.0 & 1.2 & 6.5 & 29.0 & 14.8 & 12.4 & 1.8 & 1.2 & 1.2 & 0.6 & $\overline{0.6}$ \\
\hline
\end{tabular}

In particular, the findings of the present study show that the RAsA is composed of 6.84 sentences distributed as follows:

Table 3. Distribution of sentences in RAsA

\begin{tabular}{llllllllll}
\hline & BI & BI/IG & IG & PS & R & C & ME/R & PS/ME & TOTAL \\
\hline Number of keys per RA introduction & 1.1 & 0.1 & 0.4 & 0.7 & 3.3 & 1.1 & 0.2 & 0.2 & $\mathbf{6 . 8 4}$ \\
\hline
\end{tabular}

The table above identifies the number of keys that are mentioned in the analyzed biology RAsA. It clarifies the dominance of results and conclusion sentences.

\subsection{Suggested Number of Sentences}

In order to suggest a reasonable number of sentences that can be used by researchers when writing RAsA in biology, there is a need to provide decimal numbers. In order to suggest the Suggested Number of Sentences (SNS) the researcher considered all numbers that are equal or above 0.4 as 1 and all numbers under it as 0 . This aims at suggesting a logical number of sentences by the end as it is not possible to write 0.5 or 0.3 of a sentence. Applying this rule, the researcher ended up having the below distribution of sentences:

Table 4. Suggested number of sentences for each RAsA

\begin{tabular}{lllllll}
\hline & BI & IG & PS & R & C & TOTAL \\
\hline NUMBER OF KEYS PER RA ABSTRACT & 1 & 1 & 1 & 3 & 1 & 7 \\
\hline
\end{tabular}

The table shows that the publishable RAsA needs to contain five types of keys forming seven sentences:

- One Background Information sentence

- One Identification of Gap sentence

- One Purpose of Study sentence

- Three Results sentences, and

- One Conclusion sentence.

This finding means that in order to write a publishable biology research article, researchers need first to write one background information sentence in which they situate and contextualize their study. Second, they need to write one identification of gap sentence in which they mention the gap they intend to fill in research in their study. Third, they need to write one purpose of study sentence where they clearly announce the aim behind their study. Fourth, the need to write three main results they reached in their study before finally drawing one conclusion out of them.

In their turn, each RL abstract is shown to be composed of 8.89 different move. The following table shows the distribution of the moves per research letter.

Table 5. Number of keys per RL abstract

\begin{tabular}{|c|c|c|c|c|c|c|c|c|c|c|c|c|c|c|c|}
\hline & BI & JS & IG & PS & RS & PR & $\mathbf{R}$ & C & PR/BI & ME & $\mathrm{R} / \mathrm{C}$ & $\mathrm{PR} / \mathrm{IG}$ & $\mathrm{ME} / \mathrm{R}$ & FR & TOTAL \\
\hline $\begin{array}{l}\text { Number of keys } \\
\text { per RL abstract }\end{array}$ & 1.1 & 0.1 & 0.5 & 1.2 & 0.1 & 0.6 & 2.6 & 1.3 & 1.1 & 0.2 & 0.1 & 0.1 & 0.1 & 0.1 & 8.89 \\
\hline
\end{tabular}


The table above shows the distribution of keys across every RL analyzed. It clearly reveals the dominance of the results section. Applying the same methodology and in order to suggest a reasonable number of sentences that can be used by researchers when writing RLsA in biology, there is a need to provide decimal numbers. In order to suggest the Suggested Number of Sentences (SNS) the researcher considered all numbers that are equal or above 0.4 as 1 and all numbers under it as 0 . Applying this rule, the researcher ended up having the below distribution of sentences:

Table 6. Suggested number of sentences for each RAsA

\begin{tabular}{lllllllll}
\hline & BI & PR/BI & PR & IG & PS & R & C & TOTAL \\
\hline Number of keys per RL abstract & 1 & 1 & 1 & 1 & 1 & 3 & 1 & $\mathbf{9}$ \\
\hline
\end{tabular}

Seven types of sentences are found to be making up the biology RL genre. These types are the following:

- Background Information

- Identification of Gap

- Purpose of Study

- Previous Research

- Previous Research melted with Background Information

- Results

- Conclusion

It seems that at the abstract level, the RL is richer than the RA as it outnumbers it in terms of type and quantity of sentences. This could be attributed to the need to summarize the most appealing points in the RL at the abstract level to get more attention. It seems that this genre is securing its niche in publications sphere by being practical and up to the point through focusing on what researchers expect from publications in a world characterized by speed. Giving readers what they need in a direct and thorough way is what is probably, interalia, raising attention to this genre.

The table above identifies the required kind and number of sentences to write a publishable RL. It shows that researchers need to start with a Background Information sentence followed by a Previous Research sentence followed by one Previous Research melted with Background Information sentence. Researchers need to resort then to writing an Identification of Gap sentence followed by a Purpose of Study one. After that, they need to write a, then Results sentences, before ending with one Conclusion sentence. This confirms the findings of Melliti (2017) that RLs abstracts are composed of three main phases

- $\quad$ The Introductory Phase (IP)

- The Contextualization Phase (CP)

- The Findings Phase (FP)

In the present study, and based of the phases identified by Melliti (2017), three types of sentences fall into the IP, which are Background Information, Previous Research, and Previous Research melted with Background Information. The CP phase is exemplified by Identification of Gap and Purpose of Study moves while the FP is represented by the Results and the Conclusion keys.

Needless to mention that the suggested number of sentences is identified through resorting to the data collected, but the order of these sentences is based on the researcher knowledge of the genre as well as the logical layout of research papers in general.

It could be noted that there are two kinds of sentences that are mentioned in the RL genre but not the RA one are:

- Previous Research

- Previous Research melted with Background Information

Regarding the PR and PR/BI case, their absence in the RAsA could be interpreted by the fact that this genre reserves a whole section in the body to review previous literature and provide background information about the topic in an extensive way compared to the RL genre (Melliti, 2017). The presence of these moves in RLsA could be attributed to the fact that it is hardly dealt with in the body sections (Melliti, 2017).

The present study shows that there are differences between RLsA and RAsA in terms of generic structure. 
However, it shows also that there is overlap as they both invest a similar set of keys or functions. These differences and overlaps make it imperative to teach English for publication purposed to graduate and postgraduate students. It would equip them with the necessary tools to write publishable research letters and research articles not only at the abstract level but also the other sections. Developing a course that exposes the internal structure of these genres and gives them practice on how to write them can assist Anglophone and non-Anglophone researchers in their endeavor to publish their research studies (Melliti, 2019).

\section{Conclusion}

The present study aimed at identifying the generic structure of research letters and research articles' abstracts through using Swales (2004) CARS model and Melliti (2017) CARL model. The study found that RLsA are richer than RAsA in terms of keys. It managed also to identify the exact number and kind of sentences required to write both genres and have ones' research paper published. Research in this area of investigation has several pedagogical and research related implications that are mainly related to genre teaching. Further research may need to focus on other disciplines, other than biology, in order to uncover their hidden generic structure and compare it to the present study.

\section{References}

Badger, R. (2003). Legal and general: Towards a genre analysis of newspaper law reports. English for Specific Purposes, 22, 249-263. https://doi.org/10.1016/S0889-4906(02)00020-0

Bakhtin, M. (1986). Speech genres and other late essays. Austin: University of Texas Press.

Berkenkotter, C., \& Huckin, H. (1995). Genre knowledge in disciplinary communication: Cognition, culture, power. Hillsdale, NJ: Erlbaum. https://doi.org/10.2307/358302

Bhatia, V. K. (1993). Analysing genre: Language use in professional settings. London: Longman.

Bhatia, V. K. (1997). Genre-mixing in academic introductions. English for Specific Purposes, 16(3), 181-195. https://doi.org/10.1016/S0889-4906(96)00039-7

Biber, D., Connor, U., \& Upton, T. A. (2007). Discourse on the move. Using corpus analysis to describe discourse structure. Amsterdam and Philadelphia: John Benjamins Publishing Company. https://doi.org/10.1075/scl.28

Brett, P. (1994). A Genre analysis of the results section of sociology articles. English for Specific Purposes, 13(1), 47-59. https://doi.org/10.1016/0889-4906(94)90024-8

Bruce, I. (2009). Results sections in sociology and organic chemistry articles: A genre analysis. English for Specific Purposes, 28(2), 105-124. https://doi.org/10.1016/j.esp.2008.12.005

Connor, U. (1996). Contrastive rhetoric: Cross-cultural aspects of second language writing. Cambridge: Cambridge University Press. https://doi.org/10.1017/CBO9781139524599

Del Arbol, V. (2005). A genre based study of biomedical editorials and letters to the editor: A contrastive analysis. Ibérica, 10, 145-160.

Flowerdew, J., \& Dudley-Evans, T. (2002). Genre analysis of editorial letters to international journal contributors. Applied Linguistics, 23(4), 463-489. https://doi.org/10.1093/applin/23.4.463

Gotti, M. (2007). Identity and cross-cultural communication. Proceedings of the 72nd Annual Convention of The Association for Business Communication, Oct. 10-12, 2007, Washington, DC.

Henry, A., \& Roseberry, R. L. (2001). A narrow-angled corpus analysis of moves and strategies of the genre: Letter of application. English for Specific Purposes, 20, 153-167. https://doi.org/10.1016/S0889-4906(99)00037-X

Holmes, R. (1997). Genre analysis, and the social sciences: An investigation of the structure of research article discussion sections in three disciplines. English for Specific Purposes, 16(4), 321-337. https://doi.org/10.1016/S0889-4906(96)00038-5

Hopkins, A., \& Dudley-Evans, T. (1988). A genre-based investigation of the discussion sections in articles and dissertations. English for Specific Purposes, 7(2), 113-121. https://doi.org/10.1016/0889-4906(88)90029-4

Hyon, S. (1996). Genre in three traditions: Implications for ESL. TESOL Quarterly, 30(4), 693-722. https://doi.org/10.2307/3587930

Kanoksilapatham, B. (2005). Rhetorical structure of biochemistry research articles. English for Specific Purposes, 24(3), 269-292. https://doi.org/10.1016/j.esp.2004.08.003 
Lim, J. M. H. (2006). Method sections of management research articles: A pedagogically motivated qualitative study. English for Specific Purposes, 25(3), 282-309. https://doi.org/10.1016/j.esp.2005.07.001

Maci, S. (2009). The Migration of scientific knowledge into alternative forms of research articles: The case of medical research letters. In D. Torretta, M. Dossena \& A. Sportelli (Eds.), Forms of migration. Migration of forms (pp. 479-495). Proceedings of the 23rd AIA Conference. Language Studies. Bari: Progedit.

Magnet, A., \& Carnet, D. (2006). Letters to the editor: Still vigorous after all these years? A presentation of the discursive and linguistic features of the genre. English for Specific Purposes, 25, 173-199. https://doi.org/10.1016/j.esp.2005.03.004

Martin, J. R., Christie, F., \& Rothery, J. (1987). Social processes in education: A reply to Sawyer and Watson (and others). In I. Reid (Ed.), The place of genre in learning (pp. 58-82). Geelong: Centre for Studies in Literacy Education, Deakin University (Typereader Publications 1).

Melliti, M. (2016). Generic structure of research letters' introductions: Create a research letter introduction model (CARL introduction model). TAYR Quarterly, 3(1), 10-44. https://doi.org/10.31561/2014tq

Melliti, M. (2017). Evaluation of generic structure of research letters body section: Create a research letter body section model. In S. Hidri \& C. Coombe (Eds.), Evaluation in foreign language education in the Middle East and North Africa (pp. 127-142). Basel: Springer. https://doi.org/10.1007/978-3-319-43234-2_7

Melliti, M. (2019). Publish or Perish: The Research Letter Genre and Non-Anglophone Scientists' Struggle for Academic Visibility. In S. Hidri (Ed.), English Language Teaching Research in the Middle East and North Africa (pp. 225-253). Switzerland: Palgrave Macmillan. https://doi.org/10.1007/978-3-319-98533-6_11

Nwogu, K. N. (1991). Structure of science popularizations: A genre-analysis approach to the schema of popularized medical texts. English for Specific Purposes, 10(2), 111-123. https://doi.org/10.1016/0889-4906(91)90004-G

Ozturk, I. (2007). The textual organization of research article introductions in applied linguistics: Variability within a single discipline. English for Specific Purposes, 26(1). 25-38. https://doi.org/10.1016/j.esp.2005.12.003

Paltridge, B. (1997). Genres, frames and writing in research settings. Amsterdam: John Benjamins. https://doi.org/10.1075/pbns.45

Posteguillo, S. (1999). The schematic structure of computer science research articles. English for Specific Purposes, 18(2), 139-158. https://doi.org/10.1016/S0889-4906(98)00001-5

Rutkowsky, J. L., \& Ehrenfest, D. M. (2012). Research letters: A new editorial format for the rapid disclosure of innovative data and concepts, didactic demonstrations, and scientific discussions. Journal of Oral Implantology, 38(2), 101-103. https://doi.org/10.1563/AAID-JOI-D-12-Editorial.3802

Salager-Meyer, F. (1992). A text-type and move analysis study of verb tense and modality distribution in medical English abstracts. English for Specific Purposes, 11(2), 93-113. https://doi.org/10.1016/S0889-4906(05)80002-X

Salager-Meyer, F. (2006). Medical discourse: Structured abstracts. In K. Brown (Ed.), The Encyclopedia of Language and Linguistics (2nd ed., pp. 717-720). London: Elsevier Ltd. https://doi.org/10.1016/B0-08-044854-2/04272-3

Samraj, B. (2002). Introductions in research articles: Variations across disciplines. English for Specific Purposes, 21(1), 1-17. https://doi.org/10.1016/S0889-4906(00)00023-5

Samraj, B. (2008). A discourse analysis of master's theses across disciplines with a focus on introductions. Journal of English for Academic Purposes, 7(1), 55-67. https://doi.org/10.1016/j.jeap.2008.02.005

Skelton, J. R. (1994). Analysis of the structure of original research papers: An aid to writing original papers for publication. British Journal of General Practice, 44(387), 455-459.

Swales, J. (1990). Genre analysis: English in academic and research settings. Cambridge: Cambridge University Press.

Swales, J. M. (1984). Research into the structure of introductions to journal articles and its application to the teaching of academic writing. In R. Williams, J. M. Swales \& J. Kirkman (Eds.), Common ground: Shared interests in ESP and communication studies (pp. 77-86). New York: Pergamon.

Swales, J. M. (2004). Research genres: Explorations and applications. Cambridge: Cambridge University Press. 
https://doi.org/10.1017/CBO9781139524827

Swales, J. M., \& Najjar, H. (1987). The writing of research article introductions. Written Communication, 4(2), 175-191. https://doi.org/10.1177/0741088387004002004

Taylor, G., \& Chen, T. (1991). Linguistic, cultural, and subcultural issues in contrastive discourse analysis: Anglo-American and Chinese scientific texts. Applied Linguistics, 12(3), 319-336. https://doi.org/10.1093/applin/12.3.319

Thompson, D. K. (1993). Arguing for experimental "facts" in science. Written Communication, 10(1), 106-128. https://doi.org/10.1177/0741088393010001004

Thompson, S. E. (1994). Frameworks and contexts: A genre-based approach to analyzing lecture introductions. English for Specific Purposes, 13(2), 171-186. https://doi.org/10.1016/0889-4906(94)90014-0

Wahl-Jorgensen, K. (2007). Journalists and the public: Newsroom culture, letters to the editor, and democracy. Cresskill, NJ: Hampton Press.

Webber, P. (1994). The function of questions in different medical journal genres. English for Specific Purposes, 13(3), 257-268. https://doi.org/10.1016/0889-4906(94)90005-1

Williams, I. A. (1999). Results section of medical research articles: Analysis of rhetorical categories for pedagogical purposes. English for Specific Purposes, 18(4), 347-365. https://doi.org/10.1016/S0889-4906(98)00003-9

\section{Copyrights}

Copyright for this article is retained by the author, with first publication rights granted to the journal.

This is an open-access article distributed under the terms and conditions of the Creative Commons Attribution license (http://creativecommons.org/licenses/by/4.0/). 